\title{
Research Progress in Dehydration Technology of Bischofite for Preparing Anhydrous Magnesium Chloride
}

\author{
Xuyong Liu, Xiangmei Cui * \\ (College of Chemical Engineering, Qinghai University, Xining, 810016, China) \\ * Corresponding author. E-mail: cuixiangmei1208@163.com
}

\begin{abstract}
Keywords: Bischofite; Dehydration Technology; Anhydrous Magnesium Chloride; Partially Hydrated Magnesium Chloride.

Abstract: Abundant soluble magnesium salts with low impurity were produced as by-product in some industries of Qinghai. These soluble magnesium salts were exploited more easily than some solid minerals, such as magnesites, dolomite minerals, which could accord with the standards of electrolytic process for preparing magnesium materials under rough purification processing. Several different routes on dehydration technology of bischofite $\left(\mathrm{MgCl}_{2} \cdot 6 \mathrm{H}_{2} \mathrm{O}\right)$ for preparation of anhydrous magnesium chloride $\left(\mathrm{MgCl}_{2}\right)$ are reviewed in this article, including the partially hydrated magnesium chloride $\left(\mathrm{MgCl}_{2} \cdot \mathrm{nH}_{2} \mathrm{O}, \mathrm{n}<6\right)$. In order to improve the quality of product $\left(\mathrm{MgCl}_{2}\right.$ or $\mathrm{MgCl}_{2} \cdot \mathrm{nH}_{2} \mathrm{O}$ ), a few better proposals of improved dehydration technology are proposed. In dehydration process, many factors should be taken into consideration, such as economic benefits, production efficiency, environmental problems, purity.
\end{abstract}

\section{Introduction}

Magnesium is a significant nonferrous metal and could be applied to manufacture various kinds of magnesium materials, including binary and multicomponent alloys ordinarily [1,2], which have the characters of low density [3], high strength [4], specific plasticity [5], better damping capacity [6], fine electromagnetic interfere shielding [7], good mechanical properties [8] etc. However, a large amount of bischofite was produced as by-product or industrial trailings in numerous technology of exploiting abundant salt lake resources $[9,10]$. The discharge of bischofite without rational disposal could cause terrible environment pollution and even some bischofite was disposed in the way of piling up directly, which was also a tremendous waste of resources. The phenomenon is called "magnesium disaster" in salt lake chemical industry [11], so more measures of comprehensive exploitation technology on bischofite should be developed valuably. Most of bischofite utilization aim at achieving the goal that coordinated water molecules are dehydrated to obtain anhydrous magnesium chloride, then anhydrous magnesium chloride is distributed to produce other kinds of magnesium products. Many patents $[12,13]$ have been applied in practical production. In this article the different dehydration technology of bischofite were reviewed, which focuses on how to improve the production efficiency.

\section{Dehydration Data of Bischofite By TG-DSC}

The structure of magnesium chloride hexahydrate $\left(\mathrm{MgCl}_{2} \cdot 6 \mathrm{H}_{2} \mathrm{O}\right)$ is central symmetric octahedra. The crystal structure parameters of $\mathrm{MgCl}_{2} \cdot 6 \mathrm{H}_{2} \mathrm{O}$ is determined primitively in 1934 [14]. $\mathrm{MgCl}_{2} \cdot 6 \mathrm{H}_{2} \mathrm{O}$ crystallizes in moloclinic space group $\mathrm{C} 2 / \mathrm{m}$, as illustrated in Fig.1, which showed that the crystal packing in a parallel projection approximately down the crystallographic $\mathrm{c}$ axis. The lattice parameters were listed in the corresponding reference [15], where the parameters and structures of $\mathrm{MgCl}_{2} \cdot \mathrm{nH}_{2} \mathrm{O}(\mathrm{n}=0,1,2,4,6)$ were identified in detail.

With the thermogravimetry and differential scanning calorimetry analysis curve (TG-DTA) of bischofite [16,17], we could conclude that four main periods existed during dehydration of bischofite under the condition of continuous heating stage. We conducted an experiment TG-DSC of $\mathrm{MgCl}_{2} \cdot 6 \mathrm{H}_{2} \mathrm{O}$. As shown in Fig.2, the mass change curve presented four gradients obviously. To a molecule of $\mathrm{MgCl}_{2} \cdot 6 \mathrm{H}_{2} \mathrm{O}$, in the first step, from normal temperature to $125.9^{\circ} \mathrm{C}$, the mass decreased 
$6.62 \%$, and this dehydration stage corresponded to 0.75 molecule of $\mathrm{H}_{2} \mathrm{O}$ equivalently. The second period was from $125.9^{\circ} \mathrm{C}$ to $173.8^{\circ} \mathrm{C}$, during which mass decreased $23.79 \%$, and the mass reduced the maximum among four dehydration stages. The corresponding molecule number of crystal $\mathrm{H}_{2} \mathrm{O}$ was 3.43 in the first and second periods. Mass decreased $14.37 \%$ in the third stage , and the temperature ranged from $173.8^{\circ} \mathrm{C}$ to $205.9^{\circ} \mathrm{C}$. The former three dehydration periods of bischofite reached 5.00 molecules of $\mathrm{H}_{2} \mathrm{O}$ equivalently. In the last dehydration stage, the mass decreased $10.42 \%$ from $205.9^{\circ} \mathrm{C}$ to $261.4^{\circ} \mathrm{C}$. In the four periods, the mass decreased $55.20 \%$ totally, which was equivalent to that 6.23 molecules of $\mathrm{H}_{2} \mathrm{O}$ was dehydrated in the whole dehydration periods. Where the deviation mainly happened was in the third and fourth dehydration stages, because high temperature resulted in hydrolysis reactions of partially hydrated magnesium chloride $\left(\mathrm{MgCl}_{2} \cdot \mathrm{nH}_{2} \mathrm{O}\right)$ and the main corresponding hydrolysis compounds were basic magnesium chloride $[\mathrm{Mg}(\mathrm{OH}) \mathrm{Cl}]$ and $\mathrm{MgO}$ and some other irregular impurities. These conclusions were confirmed finally by means of X-ray diffraction analysis. The results were close to the research data [18].

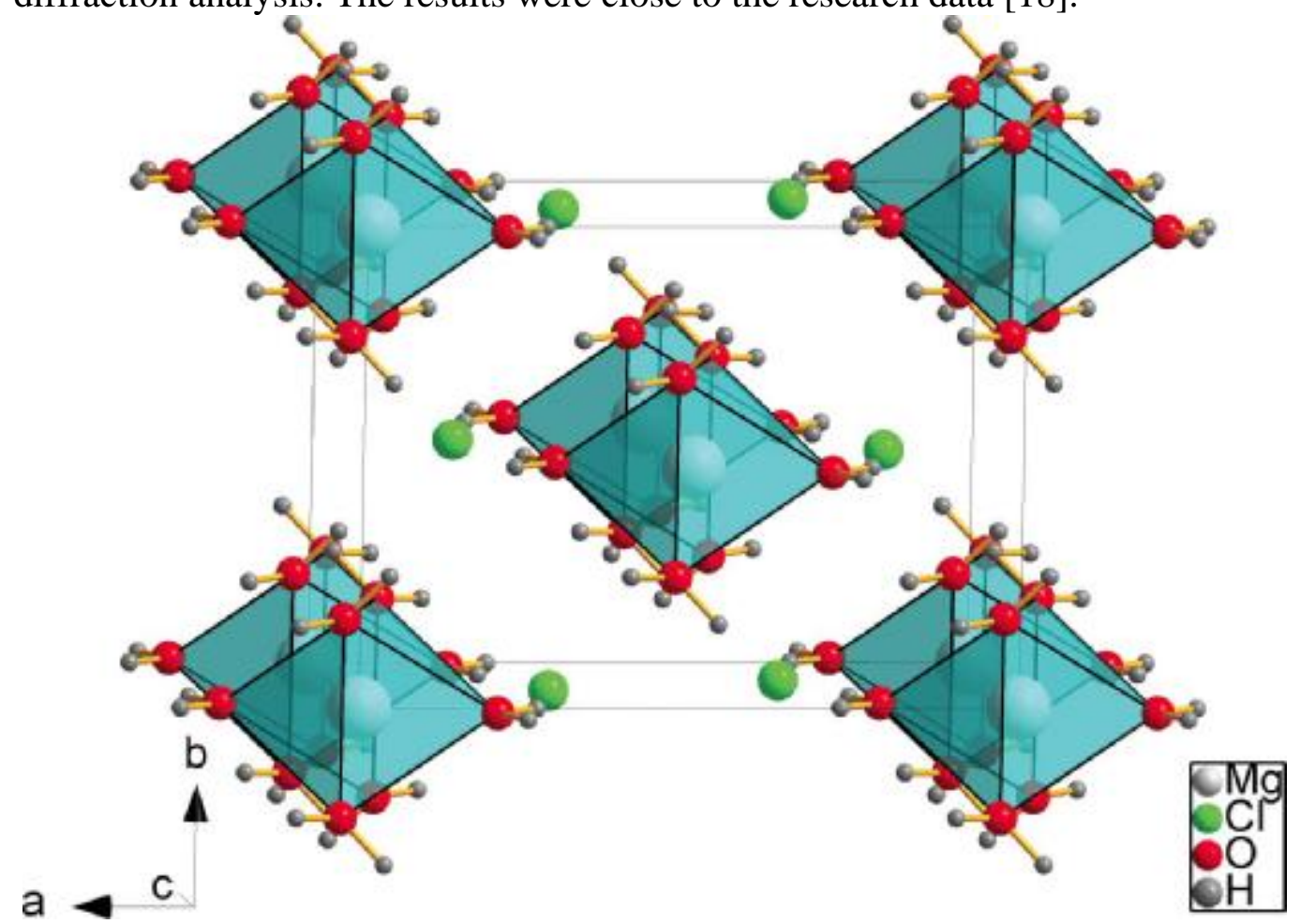

Fig.1 The crystal packing of $\mathrm{MgCl}_{2} \cdot 6 \mathrm{H}_{2} \mathrm{O}$ in a parallel projection approximately down the crystallographic c axis.

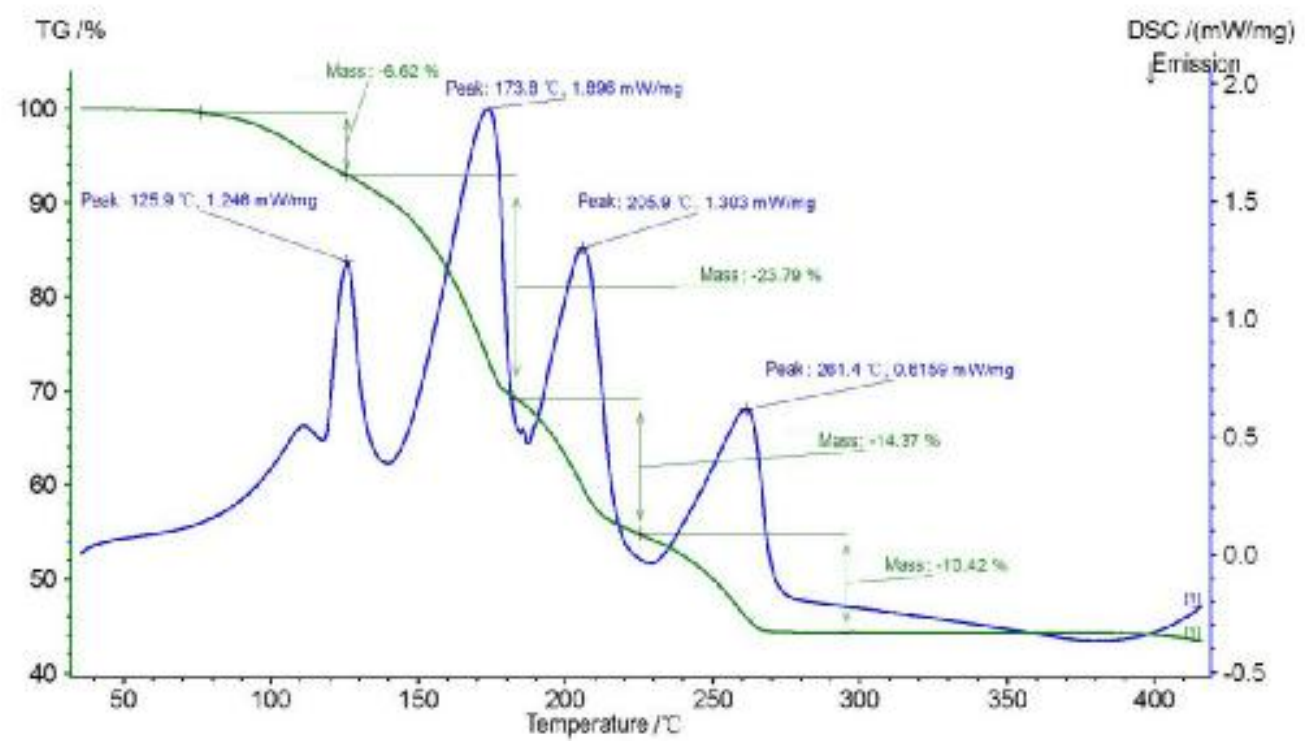

Fig.2 TG-DSC curves of bischofite 


\section{Dehydration of Bischofite}

\section{Dehydration by Shielding Gas}

With the rise of dehydration temperature, $\mathrm{MgO}$ and $\mathrm{Mg}(\mathrm{OH}) \mathrm{Cl}$ were produced increasingly in the form of by-products. In order to inhibit these by-products formation and reduce energy consumption, some dehydration technology of bischofite produced $\mathrm{MgCl}_{2}$ in the protection gas atmosphere of chlorine or hydrogen chloride gas [19]. The production conditions could contribute to restraining the proceeding of hydrolysis reactions, then the technology would produce high-purity $\mathrm{MgCl}_{2}$ effectively and reduce the hydrolysis rate as much as possible through controlling proper concentration of shielding gas. One specific procedure [20] was as follows : (1) the magnesium chloride mother liquor was concentrated preliminarily; (2) concentrated liquor was produced in the form of $\mathrm{MgCl}_{2} \cdot 2 \mathrm{H}_{2} \mathrm{O}$ under the heating air flow at $100^{\circ} \mathrm{C} \sim 200^{\circ} \mathrm{C}$; (3) then product $\mathrm{MgCl}_{2} \cdot 2 \mathrm{H}_{2} \mathrm{O}$ was treated in the shielding gas atmosphere of $\mathrm{Cl}_{2}$ or $\mathrm{HCl}$ gas at $620^{\circ} \mathrm{C} \sim 650^{\circ} \mathrm{C}$, of which ultimate $\mathrm{MgCl}_{2}$ content exceeded $95 \%$ and $\mathrm{MgO}$ content was lower than $0.5 \%$.

The method of shielding gas dehydration should be manipulated in the appropriate concentration of $\mathrm{Cl}_{2}$ or $\mathrm{HCl}$, which benefited the process of non-equilibrium state and reaction kinetics conditions, such as reaction degree, energy consumption, hydrolysis rate, and reaction time. The technology had the advantages of great automation and could produce higher purity of $\mathrm{MgCl}_{2}$, and suppressed the hydrolysis reaction effectively. The deficiencies of shielding gas dehydration were that the technology consumed lots of $\mathrm{Cl}_{2}$ or $\mathrm{HCl}$ without good recycling, high energy consumption. What's more, the production equipment was subjected to serious corrosion, and parts of $\mathrm{HCl}$ may attach to the surface of $\mathrm{MgCl}_{2}$.

In an American patent [21], shielding gas dehydration technology was different, which adopted two-stage dehydration. The first stage proceeded in spraying dryer to mix $\mathrm{MgCl}_{2} \cdot \mathrm{nH}_{2} \mathrm{O}(\mathrm{n}=0.5 \sim 1.5)$ with carbon to form much small caking, and the bulk density of small caking was between $0.6 \mathrm{~g} / \mathrm{L}$ and $1.3 \mathrm{~g} / \mathrm{L}$ and dimension distribution was between $1.5 \mathrm{~cm}$ and $5 \mathrm{~cm}$. The second stage was carried out in the atmosphere of $\mathrm{Cl}_{2}$ at $200^{\circ} \mathrm{C} \sim 300^{\circ} \mathrm{C}$ for $2 \sim 4$ hours. The end high-purity product $\mathrm{MgCl}_{2}$ met the requirements of electrolytic conditions to prepare magnesium. If product $\mathrm{MgCl}_{2}$ contained impurity beyond the standard, electrolysis process consumed more raw materials and $\mathrm{Cl}_{2}$, and including a size of disadvantageous factors, such as low efficiency, poor quality, and more slag.

\section{Dehydration by Complex Salt Methods}

\section{Dehydration by Potassium Carnallite Complex Salt Method}

According to definite proportion with bischofite and potassium chloride as raw materials, these traditional technology synthesized potassium carnallite complex $\left(\mathrm{KCl} \cdot \mathrm{MgCl}_{2} \cdot 6 \mathrm{H}_{2} \mathrm{O}\right)$ by reference of the ternary phase diagrams [22] to achieve the good effect of dehydration. In the circumstance, evaporation of salt lake brine was simulated [23], which was demonstrated that $\mathrm{KCl} \cdot \mathrm{MgCl}_{2} \cdot 6 \mathrm{H}_{2} \mathrm{O}$ was synthesized easily with low concentration in ordinary conditions. The corresponding double-chamber boiling furnace was ever applied to produce $\mathrm{KCl} \cdot \mathrm{MgCl}_{2}$ material [24]. The main operation steps were simple as follows: the base materials were added into the double-chamber boiling furnace, and heating carrier gas was injected to guarantee stable boiling stage in the first chamber under $150^{\circ} \mathrm{C} \sim 160^{\circ} \mathrm{C}$. Then carrier gas conditions were adjusted higher to keep in stable state of temperature of the second chamber reach $180^{\circ} \mathrm{C} \sim 200^{\circ} \mathrm{C}$ for proper time. The entire reaction process was in the situation of continuous feeding and continuous discharging, which was a typically chemical technology. What should be focused on was that the feeding in the first chamber should be distributed uniformly, otherwise production caking phenomenon occurred in a high degree that might cause difficulty of operation. The final recovery ratio of $\mathrm{MgCl}_{2}$ reached $91.5 \%$ and the content of $\mathrm{MgCl}_{2}$ was between $51 \% \sim 53 \%$, of which the products in this technology met the requirements with the content of $\mathrm{MgO}$ below $0.5 \%$.

This production method was a typical combination technology with reutilization of two salt lake resources simultaneously. There were large amounts of dust carried by heating carrier gas in 
emissions, so the technology should be improved to increase the production efficiency and the yield of dust and recycle energy taken away.

\section{Dehydration by Ammonium Carnallite Complex Salt Method}

High-purity $\mathrm{MgCl}_{2}$ could be prepared by the method of utilizing analytical-grade $\mathrm{NH}_{4} \mathrm{Cl}[25,26]$ or ammonia gas and bischofite as raw materials, and analytical-grade alumina as covering agent [27]. The pretreatment of raw materials was that bischofite should be maintained at $120^{\circ} \mathrm{C}$ for $2 \sim 20$ hours to guarantee the number of crystal water below 4, namely $\mathrm{MgCl}_{2} \cdot \mathrm{nH}_{2} \mathrm{O}(\mathrm{n}=0.1$ to 4). In the reaction design, the alumina could suppress decomposition of $\mathrm{NH}_{4} \mathrm{Cl}$ efficiently and isolate $\mathrm{MgCl}_{2}$ from ambient atmosphere. The $\mathrm{MgCl}_{2} \cdot \mathrm{nH}_{2} \mathrm{O}$ and solid $\mathrm{NH}_{4} \mathrm{Cl}$ were mixed evenly by milling with a suitable proportion into a corundum crucible to synthesize ammonium carnallite complex $\left(\mathrm{NH}_{4} \mathrm{Cl} \cdot \mathrm{MgCl}_{2} \cdot \mathrm{nH}_{2} \mathrm{O}\right)$. Then the mixtures with an appropriate thickness of alumina $1.3 \mathrm{~cm}$ above as covering agent were put in muffle furnace. Over a period of time the reaction temperature was set in an optimizing range. Subsequently, the mixtures were kept at $700^{\circ} \mathrm{C}$ for 1 hour to ensure the excessive $\mathrm{NH}_{4} \mathrm{Cl}$ removed thoroughly. Through exploration of multiple orthogonal experiments, the reaction rules could be concluded as follows: $\mathrm{MgCl}_{2} \cdot \mathrm{nH}_{2} \mathrm{O}(\mathrm{n}=0.1$ to 4$)$ reacted with $\mathrm{NH}_{4} \mathrm{Cl}$ to form $\mathrm{NH}_{4} \mathrm{Cl} \cdot \mathrm{MgCl}_{2} \cdot \mathrm{nH}_{2} \mathrm{O}$, which could facilitate dehydration process. Gradually, the crystal water was dehydrated, and the part $\mathrm{NH}_{4} \mathrm{Cl}$ of $\mathrm{NH}_{4} \mathrm{Cl} \cdot \mathrm{MgCl}_{2} \cdot \mathrm{nH}_{2} \mathrm{O}$ began decomposition and volatilization.

Although this method could produce the high-purity product $\mathrm{MgCl}_{2}$ and the minimum value of $\mathrm{MgO}$ could achieve below $0.02 \%$, the technology route was restricted in a small amount of production and batch production. The heating energy was released without reasonable recycling use. Inefficiency was the most evident defect, which has well room for improvement.

\section{Dehydration by Aniline Hydrochloride Complex Salt Method}

There were two routes of dehydration of aniline hydrochloride complex salt method through the same intermediate of $\mathrm{MgCl}_{2} \cdot \mathrm{C}_{6} \mathrm{H}_{5} \mathrm{NH}_{2} \cdot \mathrm{HCl} \cdot 6 \mathrm{H}_{2} \mathrm{O}$, and the main distinction was the experimental equipment between the two routes mentioned above. One set of experimental equipment was simulating fixed bed, the other one was fluidized bed. Large amounts of thermodynamics research data indicated that there was no hydrolysis reaction during the heating decomposition of $\mathrm{MgCl}_{2} \cdot \mathrm{C}_{6} \mathrm{H}_{5} \mathrm{NH}_{2} \cdot \mathrm{HCl} \cdot 6 \mathrm{H}_{2} \mathrm{O}$ [18].

In one experimental route the whole dehydration process of bischofite was tested in simulating fixed bed [28]. This experiment proceeded in a good condition of easy control. Firstly, hydrochloric acid and aniline were mixed uniformly with molar ratio of $1: 1$ in the simulating fixed bed for a while to form $\mathrm{C}_{6} \mathrm{H}_{5} \mathrm{NH}_{2} \cdot \mathrm{HCl}$. In the following, the bischofite of proper ratio was added into the homogeneous phase solution above, while cooling water and nitrogen of equipment were turned on respectively. The power of heating apparatus was switched on at the heating rate of $5 \sim 10^{\circ} \mathrm{C} / \mathrm{min}$. The most of free water and crystal water were dehydrated when the temperature reached $300^{\circ} \mathrm{C}$. Finally, reactants were heated continuously until it rised to required temperature (below $400^{\circ} \mathrm{C}$ ). Products were analysed by specific instruments. In the optimal experimental conditions, the final content of $\mathrm{MgCl}_{2}$ was more than $98.6 \%$, and the content of $\mathrm{MgO}$ was less than $0.38 \%$, and the content of $\mathrm{C}_{6} \mathrm{H}_{5} \mathrm{NH}_{2} \cdot \mathrm{HCl}$ was less than $0.12 \%$, the content of $\mathrm{H}_{2} \mathrm{O}$ was less than $0.68 \%$. The advantages of this method were that the decomposed aniline hydrochloride could be condensed for recycling utilization, and that reduced emission pollution. The shortages mainly included that the device is corroded badly by hydrochloric acid, and the production output was limited.

In the fluidized bed the experiment was divided into the following steps [29]: synthesis of complex salt, granulation, and thermal decomposition in fluidization. Bischofite and $\mathrm{C}_{6} \mathrm{H}_{5} \mathrm{NH}_{2} \cdot \mathrm{HCl}$ were added into reactor with correct proportion and formed fusion solution of complex salt by mixer at $180^{\circ} \mathrm{C} \sim 190^{\circ} \mathrm{C}$. The complex salt particles were produced by uniform droplets spray technology. The fusion droplets were sprayed from vibration granulation device in an appropriate vibration frequency. The fusion droplet was dripped into cooling petroleum ether to form uniform particles of complex salt. Then these complex salt particles were transferred into the fluidized bed to carry out dehydration. The carrier gas of nitrogen was adjusted in a moderate flow rate because 
nitrogen with large-flow rate would take away excessive heat and nitrogen with small-flow rate couldn't play a role effectively to take away water and $\mathrm{C}_{6} \mathrm{H}_{5} \mathrm{NH}_{2} \cdot \mathrm{HCl}$ dehydrated. The optimal conditions of thermal decomposition were explored as follows: the time of dehydration was $0.5 \mathrm{~h}$ at $300^{\circ} \mathrm{C}$ with the nitrogen in a rate of $1.6 \mathrm{~m}^{3} / \mathrm{h} \sim 1.8 \mathrm{~m}^{3} / \mathrm{h}$, and the time of removing $\mathrm{C}_{6} \mathrm{H}_{5} \mathrm{NH}_{2} \cdot \mathrm{HCl}$ was $1 \mathrm{~h}$ at $350^{\circ} \mathrm{C}$ with the nitrogen in a rate of $1.0 \mathrm{~m}^{3} / \mathrm{h} \sim 1.2 \mathrm{~m}^{3} / \mathrm{h}$. Finally, the content of $\mathrm{C}_{6} \mathrm{H}_{5} \mathrm{NH}_{2} \cdot \mathrm{HCl}$ was less than $0.12 \%$, and the content of $\mathrm{H}_{2} \mathrm{O}$ was less than $0.68 \%$. Obviously, the operation time was shortened greatly compared with the first method above, but recycling utilization of exhaust was not taken into consideration.

To the two dehydration of complex salt with $\mathrm{MgCl}_{2} \cdot \mathrm{C}_{6} \mathrm{H}_{5} \mathrm{NH}_{2} \cdot \mathrm{HCl} \cdot 6 \mathrm{H}_{2} \mathrm{O}$ as intermediate, the dehydration process was similar, which both produced high-purity $\mathrm{MgCl}_{2}$ ultimately. However, the processes were disparate. It's necessary to combine the two methods for more efficient technology, more environmental, more energy-saving, more time-saving, more abundant production etc.

\section{Dehydration by Butanol Complexation}

The foundation of dehydration was that Bischofite could react with butanol $\left(\mathrm{C}_{4} \mathrm{H}_{9} \mathrm{OH}\right)$ to form complexation, which was involved substitution reactions [30,31], namely the crystal water of bischofite was replaced partially by $\mathrm{C}_{4} \mathrm{H}_{9} \mathrm{OH}$ in the heating state. The characteristics were gripped to be applied to dehydration technology of bischofite [32]. To a molecule of $\mathrm{MgCl}_{2} \cdot 6 \mathrm{H}_{2} \mathrm{O}, 4$ molecules of inner crystal water were replaced first, and the other remaining 2 molecules were replaced next. The substitution reactions couldn't proceed completely in the synchronisation, so mixing complex compounds $\left(\mathrm{MgCl}_{2} \cdot \mathrm{xH}_{2} \mathrm{O} \cdot \mathrm{yC}_{4} \mathrm{H}_{9} \mathrm{OH}\right)$ existed in solution. In the dehydration process, two steps were implemented necessarily. One step was that butanol should be added into reactor continuously to maintain the stable mole proportion of $\mathrm{MgCl}_{2}$ to $\mathrm{C}_{4} \mathrm{H}_{9} \mathrm{OH}$, because surrounding temperature exceeded the boiling point of $\mathrm{C}_{4} \mathrm{H}_{9} \mathrm{OH}$ and $\mathrm{C}_{4} \mathrm{H}_{9} \mathrm{OH}$ was volatile easily in the condition. The other one was that ultrasonic was introduced in the period of dehydration, of which strong vibration was useful to destroy the space structure of complex. The rate of dehydration rised when prolonging the time of ultrasonic pretreatment. The water and $\mathrm{C}_{4} \mathrm{H}_{9} \mathrm{OH}$ that were distilled from reactor were separated by the means of fractionation, and $\mathrm{C}_{4} \mathrm{H}_{9} \mathrm{OH}$ was recycled. The former 4 crystal water were dehydrated easily, but the latter 2 crystal water couldn't be removed absolutely, especially the last one. Under fine operation, the dehydration ratio could reach $90.25 \%$. The analysis results showed that the dehydration efficiency factors of continuous distillation process were as the followings: ultrasonic time, temperature, the mole proportion of $\mathrm{MgCl}_{2}$ to $\mathrm{C}_{4} \mathrm{H}_{9} \mathrm{OH}$.

\section{Improvement of Technology in Theory}

According to our experiment with Figure 2, the thermal decomposition of $\mathrm{MgCl}_{2} \cdot 6 \mathrm{H}_{2} \mathrm{O}$ was shown in detail. Maybe, with the thermodynamics properties of $\mathrm{MgCl}_{2} \cdot 6 \mathrm{H}_{2} \mathrm{O}$ a series of more reasonable technology could be explored and applied to practical production. All data were demonstrated that $\mathrm{MgCl}_{2} \cdot 4 \mathrm{H}_{2} \mathrm{O}$ and $\mathrm{MgCl}_{2} \cdot 2 \mathrm{H}_{2} \mathrm{O}$ were obtained easily in the stage under direct heating from bischofite [33,34], and the purity of $\mathrm{MgCl}_{2} \cdot 4 \mathrm{H}_{2} \mathrm{O}$ and $\mathrm{MgCl}_{2} \cdot 2 \mathrm{H}_{2} \mathrm{Or}$ were very high. In theoretical technology, $\mathrm{MgCl}_{2} \cdot 4 \mathrm{H}_{2} \mathrm{O}$ or $\mathrm{MgCl}_{2} \cdot 2 \mathrm{H}_{2} \mathrm{O}$ as intermediate is produced first in the appropriate conditions, then $\mathrm{MgCl}_{2} \cdot 4 \mathrm{H}_{2} \mathrm{O}$ or $\mathrm{MgCl}_{2} \cdot 2 \mathrm{H}_{2} \mathrm{O}$ production was devoted into the second processing to combine with varied techniques of dehydration, for instance, dehydration by shielding gas, by complex salt methods, by butanol complexation. What's the worthy of learning in preliminary processing are that preparation technology is simple, low energy consumption, moderate reaction, short production period, less impurities, no pollution, little wastes etc.

\section{Exploiting Prospects}

Based on the characters of well stability and strong mechanical properties, magnesium materials involve wide application domains, super-performance alloys [35], coating [36], biomedical materials [37], lightweight alloy etc. These lightweight alloy materials are necessary 
structural materials in multitudinous fields, such as national defense [38], aviation industry [39], vehicle [40], architecture [41], which could form a layer of stable density oxidation film to prevent materials from corrosion [42]. In China soluble magnesium salt resources are widely distributed in giant reserves, especially the high level of bischofite produced in Qinghai salt lakes, which have well prospects as environmental protection materials. The developments technology of soluble magnesium salt save energy and cause environment pollution more slightly, which observes the principle of energy conservation and emission reduction and accords with our national conditions. Therefore, that the technology of the diversified research of high-purity $\mathrm{MgCl}_{2}$ is produced with bischofite as raw materials has huge rising space, which is attracting more and more attentions of enterprises. Then, all kinds of magnesium materials are produced through $\mathrm{MgCl}_{2}$. The country would support and enlarge fund investment in the fields. We can solve the serious challenges of environment pollution, and we will create considerable economics benefits. Magnesium materials are one of the most influential composites as bright prospective materials of the 21th century, which will lead the wave of exploring relative new materials.

\section{References}

[ 1 ]D. Steglicha, X. Tiana, J. Bessonb. European Journal of Mechanics A: Solids, 55, 289-303, (2016)

[ 2 ]Shuping Ge, Yi Wang, Jie Tian. Journal of Biomedical Materials Research Part B, 104, 482-487, (2016)

[ 3 ]Kevin J. Laws, Jake D. Cao, Cyndy Reddy, etc. Scripta Materialia, 88, 38-40, (2014)

[ 4 ]Hucheng Pan, Yuping Ren, He Fu, etc. Journal of Alloys and Compounds, 663, 321-331, (2016)

[ 5 ]Chang Ni, Hong Ding, Xuejun Jin. Computational Materials Science, 111, 163-174, (2016)

[ 6 ]Yujie Cui, Yunping Li, Shihai Sun, etc. Scripta Materialia, 101, 8-11, (2015)

[ 7 ]Laura R. Stein, Alexander V. Badyaev. Functional Ecology, 25, 1215-1222, (2011)

[ 8 ]Mingfan Qi, Yonglin Kang, Bing Zhou. Transactions of the Indian Institute of Metals, 69, 673-682,(2016)

[ 9 ]Xianhua Hou, Mianping Zheng. Acta Geologica Sinica, 88, 335-336, (2014)

[10]Sifeng Bi, Xiangmei Cui. Acta Geologica Sinica, 88, 294-295, (2014)

[11]Zhiming Wu, Peihua Ma. Journalof Salt Sake Research, 4, 65-72, (2007)

[12]Peihua Ma. CN, CNB021144060, (2006)

[13]Subramanian P., Selvakesavan Arunachalam, Srinivasan Laguduva K. I., etc. US, US4563339 A, (1986)

[14]Andress K. R., Gundermann J., Z. Kristallogr. 87A, 345 (1934)

[15]Kunihisa Sugimoto, Robert E. Dinnebier, Jonathan C. Hansonb. Structural Science, Crystal Engineering and Materials, 63, 235-242, (2007)

[16]Hongrui Ren, Zhen Chen, Yulong Wu, etc. Journal of Thermal Analysis and Calorimetry, 115, 1949-1960, (2014)

[17]Mironyuk, I.F., Gun'ko, V.M., Povazhnyak, M.O., etc. Applied Surface Science, 252, 4071-4082, (2006)

[18]Qianyin Ni, Yulong Wu, Mingde Yang, etc. Spectroscopy and Spectral Analysis, 31,

1747-1751, (2011)

[19]Peacy J. G, Kennedy M. W.. US, US5565080, (1986)

[20]East China university of the east. CN, 01126495.0, (2002)

[21]Council of Scientific and Industrial Research. US, US4563339 A (1986)

[22]Tianlong Deng, Huan Zhou, etc. Salt-water system phase diagram and application. Chemical Industry Press, (2003)

[23]Xiangmei Cui, Zhiming Wu, Xianming Wen, etc. Acta Geologica Sinica, 88, 305-306, (2014)

[24]Jisheng Yao, Rufan Wu. Light metals, 3, 38-42, (1988)

[25]Hyoung Choon Eom, Hyungkyu Park, Ho-Sung Yoon. Advanced Powder Technology, 21,

125-130, (2010) 
[26]Ningbo Zhou, Baizhen Chen, Xinkuai He, etc. Frontiers of Chemistry in China, 1, 384-388,(2006)

[27]Zhimin Zhang, Xuchen Lu, Feng Pan, etc. Metallurgical and materials transactions B, 44, 354-358, (2013)

[28]Husheng Hu, Mingde Yang, Yulong Wu, etc. Nonferrous Metals (Extractive Metals), 7, 17-21, (2011)

[29]Jinxin Yang, Jie Dang, Yulong Wu, etc. Journal of Salt and Chemical Industry, 4, 10-15, (2012)

[30]Detlef Schroder, Helmut Schwarz. International Journal of Mass Spectrometry, 231, 139-146, (2004)

[31]Florian Ilgen, Denise Ott, Dana Kralisch, etc. Green Chemistry, 12, 1948-1954, (1999)

[32]Shangyuan Wu, Xiangyang etc. Journal of Central South University (Science and Technology), 1, 47-51, (2006)

[33]Wanbang Xu, Shidong Wang, Minxiong Chu, etc. Journalof Salt Sake Research, 2, 22-25, (2006)

[34]Xuyong Liu, Xiangmei Cui. Chinese Chemical Society Session of the 9th National Academic Conference on Inorganic Chemistry, (2015)

[35]E. Aghion, A. Arnon. Advanced Engineering Materials, 9, 747-750, (2007)

[36]Peng Tian, Demin Xu, Xuanyong Liu. Colloids Surf B Biointerfaces, 141, 327-337, (2016)

[37]B. Ratna Sunila, T.S. Sampath Kumara, etc. Mater Sci Eng C Mater Biol Appl, 59, 356-367, (2016)

[38]Tomé C., Beyerlein I., Wang J.. Journal of the Minerals, Metals and Materials Society, 63, 19-23, (2011)

[39]Andrzej Gontarz;Anna Dziubinska. Aircraft Engineering and Aerospace Technology, 96, 356-360, (2014)

[40]Ehrenberger Simone, Friedrich Horst E.. Journal of the Minerals, Metals and Materials Society, 65, 1303-1309, (2013)

[41]Nguyen Julien, Douville Frédéric, Bouaziz, Olivier. Materials Science and Engineering: A, 660, 77-83, (2016)

[42]Lamaka, S.V., Höche, D., Petrauskas, R.P.. Electrochemistry Communications, 62, 5-8, (2016) 